\title{
Design and Implementation of Optimal PID Controller Using PLC for Al-Tahady ESP
}

\author{
Rawnaq M. Afram and Anas A. Hussien \\ Al Nahrain University /Computer Engineering, Baghdad, 00964, Iraq \\ Email: \{rawnaqmaher@yahoo.com, anasali78@yahoo.com, \} \\ Mehdi J. Marie \\ Ministry of Industry and Minerals, Baghdad, 00964, Iraq \\ Email: mehdijelo@gmail.com
}

Received: 16 March 2020; Accepted: 20 August 2020; Published: 08 October 2020

\begin{abstract}
The electrostatic precipitator (ESP) is an extensively used system in metallurgical industries and the generation of power to decrease the release of dust in the flue gas. In the design of the Electrostatic precipitator unit, gas emission uniform distribution is expected to fulfil its best aggregation performance. Programming Logic Controller (PLC) is a controller for industrial process automation and self-monitoring. A lot of industries utilized PLC to automatically control the entire process with less involvement from the human and to evade errors. In this paper, A mathematical model for Electrostatic precipitator from physical parameters and analysis has been developed. The controller is built depending on this model using the basic principle of a well-known A Proportional Integral Derivative (PID) controller to control the high voltage of the Electrostatic precipitator (ESP) by adjusting the opening of voltage and current by applying analogue signals (4-20 mA) from output cards of the PLC. The simulation results paved the way to build a practical system. building the mathematical model by using the Identification Toolbox of MATLABß Version 9.6. The system was built using Allen Bradley PLC. The effect of control parameters (PID) in the case of voltage or current has been studied to demonstrate the efficiency of the model for the precipitator and observer in the case of the control system for the Al-Tahady ESP. The PID controller was built and the best values for the Electrostatic Precipitator controller are $\left(\mathrm{K}_{\mathrm{P}}=2.3904, \mathrm{~K}_{\mathrm{I}}=3.5382, \mathrm{~K}_{\mathrm{D}}=0.3\right)$. PID controller reduces steady-state errors.
\end{abstract}

Index Terms: Electrostatic Precipitator, Programming Logic Controller (PLC), Optimal PID controller, FLS

\section{Introduction}

This paper's motivation is to support the work in Iraqi cement plants. They had been installed more than thirty years ago. The control pieces of equipment all over the factories are old and if new equipment is purchased, it is not possible to use the full benefit of its capabilities. They are run with less than their production capacity. There are a lot of pollutants released from cement plants such as Cox, Sox, Nox, and high quantities of dust. A reliable controlling system is also required to limit the harmfulness of these hazardous gases.

The ESP is used for air pollution control systems in cement plants. Its efficiency is large enough to be used in every cement factory[1,2].

There is an important role for the Electrostatic precipitator in controlling the dust pollution of manufacturing. The continuous growth in manufacturing in our country needs an extra interest in environmental protection. Especially there are more rigorous demands for the elimination of pollutants in recent years. Therefore, the electrostatic precipitator high voltage power supply needs to be reformed.

The rectifier equipment control system of the conventional electrostatic precipitator is usually had many operation mistakes which cause instability in performance conditions of the rectifier devices, like low control accuracy, incapable to measure the charge, and present the fixed parameters, tracking sparks at slow speed, etc.

The overall system of ESP consists of three main units: power supply, rappers, heaters. The mechanical iron structure of ESP in Al-Tahady is shown in Fig. 1, The ESP uses a technology that depends on a high negative voltage direct current power supply (- HVDCPS). The power supply consists of two main units: transformer-rectifier (TR) set and controller cabinet. The TR set is used to step up the low voltage to high while the bridge rectifier is used to change the AC voltage to DC with negative polarity. The TR set also sends the current and the voltage values according to[1, 3]. The best way to understand the system of operation is through the following activities: 


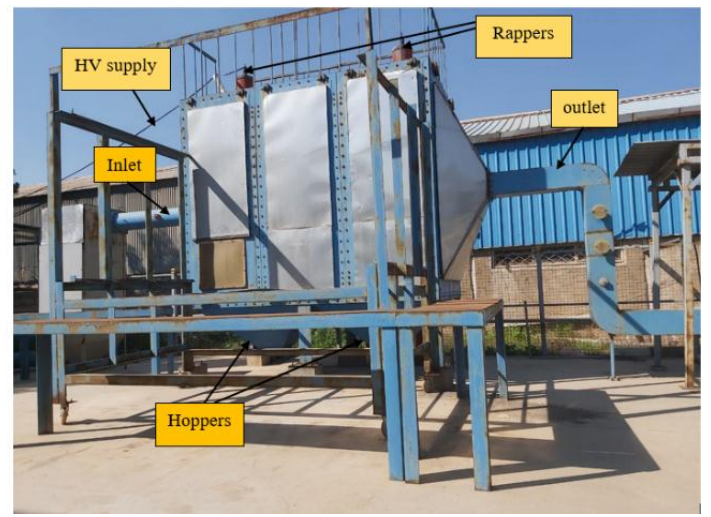

Fig.1. Al-Tahady Electrostatic precipitator

1. Ionization: Particle charging.

2.Migration: Transfer the charged small pieces to the collecting surfaces

3. Collection: Deposition of the charged small pieces on to the collecting surfaces.

4. Charge dissipation: Neutralizing the charged small pieces on the collecting surfaces.

5.Particle dislodging: Eliminating the small pieces from the collecting surface to the hopper.

6. Particle removal: transferring the small pieces from the hopper to the eliminating point.

This paper addresses the use of the Allen Bradley Bulletin 1763 MicroLogix TM 1100 PLC and PID parameters for controlling parts of the AL-Tahady ESP. Successful implementation of an experiment for controlling the operating and temperature using PLC and can control all other parameters such as pressure in the same way.

\section{Literature Review}

Reza Ezuan Samin et al [4] proposed a PID using OMRON CJIM-CPU12 PLC in the heating tank, to control temperature $\mathrm{CJ} 1 \mathrm{~W}-\mathrm{TC} 001$, where the control unit of temperature is an I/O unit that receives inputs directly from the thermocouple, The PID control is performed to set temperature by the worker using the Human Machine Interface (HMI) and the PLC controller will save the required temperature base selected by the worker.it is very difficult to control the temperature in normal control techniques. proposed to add control valves depending on the different pressure and flow rate of the transmission pipeline using PLC-based on PID controller to automatically manage the flow and pressure during transportation of petroleum products by controlling the percentage of the opening of the control valves and pumps respectively, to help the worker to keep the pressure constant. Priyanka, EB et al [5] proposed to add control valves depending on the different pressure and flow rate of the transmission pipeline using PLC-based on PID controller to automatically manage the flow and pressure during transportation of petroleum products by controlling the percentage of the opening of the control valves and pumps respectively, to help the worker to keep the pressure constant. Xue, Jian[6] Establish a mathematical model for a closed-loop hydraulic servo system to design SIEMENS S7-1500 PLC based on PID controller to achieve high accuracy in control to closed-loop.. Al Andzar, Muhammad Faqihuddin et $a l$ in [7] built a prototype of biodiesel reactor to control the process using OMRON CP1E NA20DR-A based on PID to keep the required level of temperature and for heating it to $30-65 \mathrm{c}$ temperature and stirring speed of $700 \mathrm{rpm}$ by using the heater, LM35DZ temperature sensor, and DC motor.

\section{Programming Logic Controller (Plc)}

PLC is a user-friendly microprocessor-based microcomputer contains software and hardware. The purpose of the PLC is to control the processes and operations of the manufacturing equipment.

PLC has a significant advantage in which it can be simply programmed and reprogrammed. Due to its high flexibility and reliability at the design and implementation phases, PLC has a great impact on industrial equipment control. The new PLCs are established with an advanced and versatile system of control components that can implement complicated mathematical functions and run at high speeds of a microprocessor [8]. Allen Bradley Bulletin 1763 MicroLogix $^{\text {TM }} 1100$ is used to control the ESP high voltage in Al-Tahady site. This PLC has online editing, Ethernet/IP, and an LCD panel to the family of MicroLogix. The LCD panel displays I/O status, the status of the controller, and simple functional messages. The MicroLogix 1100 controller can process wide different functions with two analogue inputs, ten digital inputs, and six digital outputs. 


\section{Pid Controller}

PID controller is a general control loop and feedback technique usually used in the manufacturing control system. A PID controller is used for error correction between a variable of a measured process and a required setpoint by calculating and outputting a corrective operation that can accordingly regulate the process. three different parameters in the calculation of the PID controller which are; the integral, proportional, and derivative values. The integral specify the reaction depends on the current error summation, the proportional value specifies the reaction to the recent error, and the rate at which the error has been changing reaction is specified by the derivative.

In the PID controller algorithm, the PID tuning three constants to provide control design for particular requirements of the process. The response of the controller can be explained concerning the responding of the controller to a degree error at which the controller exceeded the setpoint and the system oscillation degree [9].

The PID control action is calculated by,

$$
\begin{gathered}
G c=k p\left(1+\frac{K i}{K p s}+\frac{K d}{K p} s\right) \\
G(t)=k p e+k i e(t)+k d \frac{d e(t)}{d t} \\
G c=k p\left(T i T d s^{2}+T i s+\frac{1}{T i s}\right)
\end{gathered}
$$

and is shown below in Fig. 2.

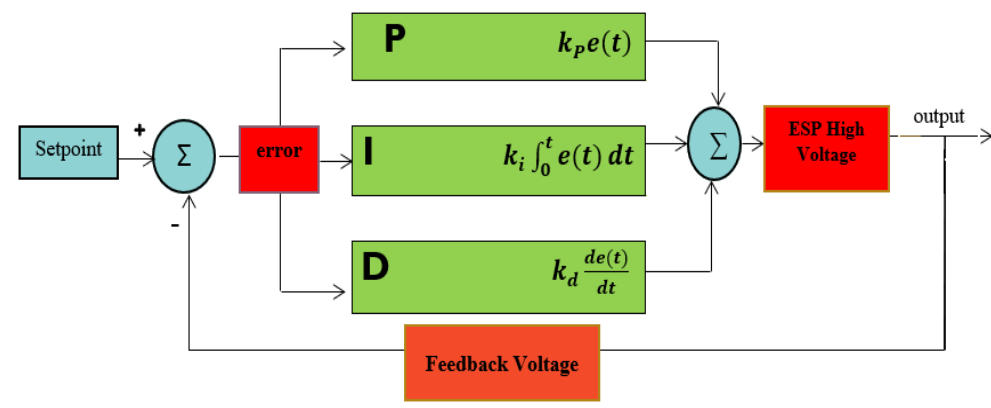

Fig.2. The PID controller for ESP

MATLAB $®$ functions are utilized to design the PID controller to make a group of parameters connected with a required feature of the controller. The PID controller is activated in MATLAB ${ }^{\circledR}$ to measure and plot the time response of the control system [10].

\section{Mathematical Model Of Esp With Pid Controller}

The ESP is distinguished for two different types of processes according to [11], these are wet and dry. The ESP is a large mechanical structure (as shown previously in Fig. 1) designed and manufactured especially. It consists mainly of discharge electrodes (sometimes called wires) and collecting plates. The plates are fixed in a vertical parallel manner to forming gas passages of $30-40 \mathrm{~cm}$ apart. The plates have discharge electrodes that are electrically insulated and sorted in rows among the passages of gas both are fixed on mechanical frames and housed with an iron container. The hall structure is isolated from the environment by glass wool.

Corona power is provided by a system of high voltage to discharge electrodes to create the electrostatic field. The charged space charges the particulate entrained in the gas when across through it. The gas stream which contains dust, fumes, and different gases receives a negative charge. Then, the gases and particles of dust are then precipitated on the plates; which is connected to the ground; creating a layer of dust on the collecting plates inside the ESP. The gathered dust layer separates from electrodes and plates by Periodic rapping.

The mathematical model of ESP is built depending on the input and the output data of the system. The input is the triggering gate to the thyristor unit and below illustrates the thyristor operation in single-phase controllers[12]. 
Ac Voltage Controllers (Single-Phase Controllers)

Two thyristors are parallelly connected to control the positive and negative parts of the input voltage. Fig. 3 shows a full-wave controller with an RL load. Assuming that thyristor T1 is fired during positive half-cycle and carries the load current. Due to circuit inductance, the T1 current won't reach zero at $(\omega t=\pi)$. When the voltage of the input begins to reach negative values, as (i1) current value is greater than zero at $(\omega \mathrm{t}=\beta)$, thyristor $\mathrm{T} 1$ is still and continue conducting. The thyristor T1 conducting angle is:

$$
\sigma=\beta-\alpha
$$

It relies on the power factor angle of the load $(\theta)$ and the delay angle $(\alpha)$ and. The input voltage, waveforms for the thyristor current, and gating pulses can be shown in Fig. 4.

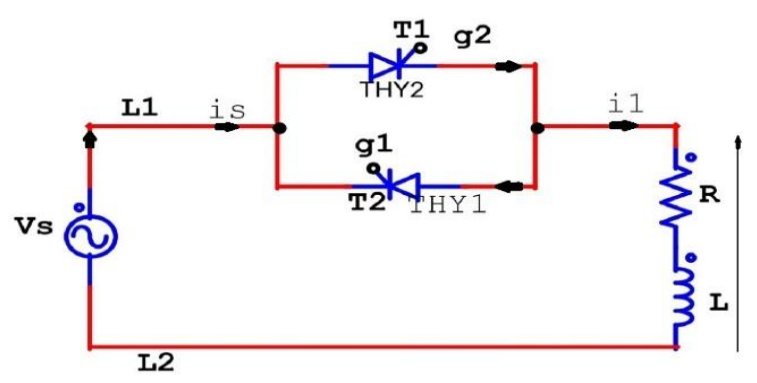

Fig.3. Full-wave controller with ESP

IF VS $=\sqrt{2} V s \sin (\omega t)$ is the input voltage and the delay angle of thyristor T1 I s $\alpha$, current of the thyristor (i1) can be obtained from:

$$
L \frac{d i}{d t}+R i=\sqrt{2} V s \sin (w t)
$$

And the solution of the above differential equation is:

$$
i 1=\frac{\sqrt{2}}{Z} v s \sin (\omega t-\theta)+A 1 e^{-(R / L) t}
$$

Where Load Impedance $\mathrm{Z}$ is:

$$
Z=\left\{R^{2}+(w L)^{2}\right\}^{0.5}
$$

And load angle $\theta$ is:

$$
\theta=\tan ^{-1}(w L / R)
$$

The constant $\mathrm{A} 1$ can be obtained from the initial condition: at $\omega \mathrm{t}=\alpha ; \mathrm{i}=0$ From equation (3) A1 can be found as:

$$
A 1=\frac{\sqrt{2} v s}{z} \sin (\alpha-\theta) e^{(R / L)\left(\frac{\alpha}{\omega}\right)}
$$

Substitution of A1 from Equation (9) in equation (6) yields:

$$
i 1=\frac{\sqrt{2} v s}{z}\left\{\sin (\omega t-\theta)-\sin (\alpha-\theta) e^{\left(\frac{R}{L}\right)\left(\left(\frac{\alpha}{w}\right)-t\right)}\right\}
$$


when current is dropped to zero and thyristor T1 is switched off, the angle $\beta$ is found from the condition is $\omega t=\beta=0$ in Eq. (10) and is given by the relation:

$$
\sin (\beta-\theta)=\sin (\alpha-\theta) e^{\left(\frac{R}{L}\right)\left(\frac{\alpha-\beta}{\omega}\right)}
$$

The angle $\beta$ referred to as extinction angle, can be obtained from this Transcendental equation and it requires an iterative way of the solution, after $\beta$ is obtained, conduction angle $\sigma$ of the thyristor T1 can be obtained from equation (4):

The r.m.s. output voltage:

$$
\begin{gathered}
V_{\text {r.m.s. }}=\left[\frac{V_{s}^{2}}{\pi} \int_{\alpha}^{\beta}(1-\cos 2 \omega t) d(\omega t)\right]^{\frac{1}{2}} \\
=V_{s}\left[\frac{1}{\pi}\left(\beta-\alpha+\frac{\sin 2 \alpha}{2}-\frac{\sin 2 \beta}{2}\right)\right]^{\frac{1}{2}}
\end{gathered}
$$

The r.m.s. thyristor current can be found from Eq. (6) as:

$$
\begin{gathered}
\mathrm{IR}=\left[\frac{1}{2 \pi} \int_{\alpha}^{\beta} i_{1}^{2} d(\omega t)\right]^{\frac{1}{2}} \\
=\frac{V_{S}}{Z}\left[\frac{1}{\pi} \int_{\alpha}^{\beta}\left\{\sin (\omega t-\theta)-\sin (\alpha-\theta) e^{\left(\frac{R}{L}\right)\left(\frac{\alpha}{\omega}-t\right)}\right\}^{2} d(\omega t)\right]^{\frac{1}{2}}
\end{gathered}
$$

and the r.m.s. the output current can be found by combining the r.m.s. the current of each thyristor as:

$$
I o=\left(I_{R}^{2}+I_{R}^{2}\right)^{\left(\frac{1}{2}\right)}=\sqrt{2} I_{R}
$$

the thyristor current average value can also be found from Eq. (16) as:

$$
\begin{gathered}
I_{A}=\frac{1}{2 \pi} \int_{\alpha}^{\beta} i 1 d(\omega t) \\
I_{A}=\frac{\sqrt{2} V s}{2 \pi z} \int_{\alpha}^{\beta}\left[\sin (\omega t-\theta)-\sin (\alpha-\theta) e^{\left(\frac{R}{L}\right)\left(\left(\frac{\alpha}{\omega}\right)-t\right)}\right] d \omega t
\end{gathered}
$$

The thyristors' signals of gating can be short pulses for the controller that has resistive loads. However, these short pulses are not appropriate for inductive loads. This can be explained by referring to Fig. 4 when thyristor T2 is fired at $(\omega t=\pi+\alpha)$, thyristor $\mathrm{T} 1$ is still conducting because of load inductance. When the thyristor T1 current dropped to zero and $\mathrm{T} 1$ is turned off at $\mathrm{wt}=\beta=\alpha+\sigma$, the thyristor T2 gate pulse has already stopped and consequently, T2 will not be turned on. As a result, only thyristor T1 will operate causing asymmetrical waveforms of output voltage and current.

This difficulty can be resolved by using continuous gate signals with a duration of $(\pi-\alpha)$ as shown in Fig. 5 .

As soon as the current of T1 falls to zero, thyristor T2 (with gate pulses as shown in Fig. 6 would be turned on. however, a continuous gate pulse increases the switching loss thyristors and requires a larger isolating transformer for the gating circuit. In practice, a train of pulses with short durations as shown in Fig. 5 are normally used to overcome these problems. As indicated in Equation (17), if the load angle $\theta$ is greater than the delay angle $\alpha$ then, the load voltage (and current) will be sinusoidal. The load current would be discontinuous and non-sinusoidal if $\theta$ is less than $\alpha$.

1- If $\alpha=\theta$, from Eq. (10)

$$
\sin (\beta-\theta)=\sin (\beta-\alpha)=0
$$

and:

$$
\beta-\alpha=\sigma=\pi
$$


2- $\alpha$ may not be less than $\theta$ as long as the conduction angle $\sigma$ cannot override $\pi$ and the load current must pass through zero. The delay angle control range is:

$$
\theta \square \alpha \square \pi
$$

3- The current won't change with $\alpha$ if $\alpha \preccurlyeq \theta$ and the thyristors gate pulses are of long-term, but the thyristors together would conduct for thyristor T1 would turn on at $\omega \mathrm{t}=\theta$. And thyristor T 2 would turn on at $\omega \mathrm{t}=\pi+\theta$.

4- The switching action of thyristors makes the equations for currents non-linear. A numerical method of solution for the thyristor conduction angle and currents is more efficient than classical techniques[13].

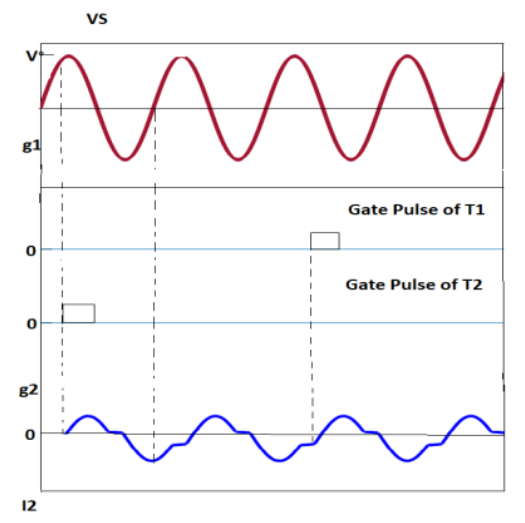

Fig.4. Phase Control of Two thyristors

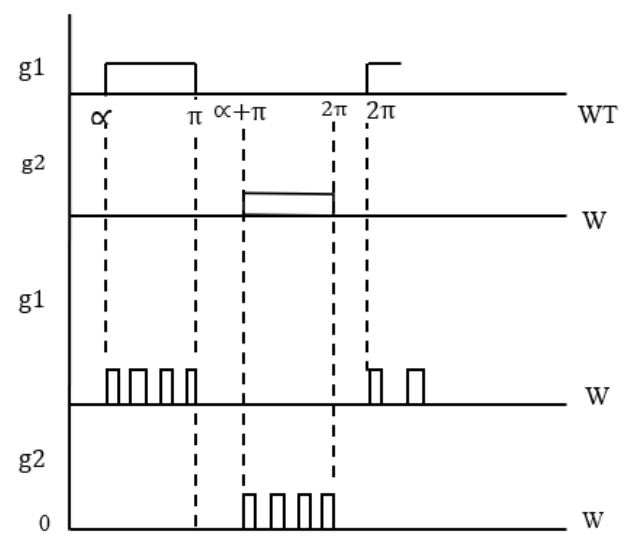

Fig.5. Continuous Gate signals

The current $(\mathrm{mA})$ and the voltage (KV) are the ESP electrical operating points. "The value of corona depends on these electrical operating points. Therefore, the whole Process of an ESP mainly depends on the applied voltage and current. The relation to corona discharge is eq. 22

$$
I=A *(V-V c)
$$

Where $A$ is a constant, $V C$ is the corona starting voltage, $I$ is the electric current and $V$ is the applied voltage. At an electrode separation $(d>5 \mathrm{~cm})$, the starting voltage of negative corona is $\left(15^{*} d \mathrm{Kv}\right)$ where $d$ is the separation between the electrodes in cm." As demonstrated in [14], this corona production field is determined experimentally, then the relationship between the electric field and corona effect is represented by

$$
E_{c}=3.126 * 10^{6} d_{r}\left[1+0.0301\left(\frac{d r}{r}\right)^{0.05}\right]
$$

Where $E c, d r, r w$ is "the corona onset field at the wire surface $(\mathrm{V} / \mathrm{m})$, the relative gas density and the radius of the wire $(\mathrm{m})$ respectively. Under the wire and direct plate, the maximum current density is given by 


$$
J=\mu \varepsilon_{0}\left(\frac{v^{2}}{l^{3}}\right)
$$

Where $J, \mu, V, l$ is maximum current density $(\mathrm{A} / \mathrm{m} 2)$, the ion mobility ( $\mathrm{m} 2 / \mathrm{Vs})$, applied voltage, and the shortest space from the wire to collecting plate respectively.

The value of the field when sparking is going to start is given by this relation.

$$
E s=6.3 * 10^{5}\left(\frac{273}{T} P\right)^{1.65}
$$

Where Es, T, $P$ is sparking field strength $(\mathrm{V} / \mathrm{m})$, absolute temperature $(\mathrm{K})$, the gas pressure (atm) respectively and an ESP collection efficiency $(\eta)$ is

$$
\eta=1-\exp (-w e f)
$$

And hence,

$$
\eta=1-\exp (-w e A / Q)
$$

Where $\omega e, f, A, Q$ is the migration velocity $(\mathrm{m} / \mathrm{s})$, the specific collection area, the area of the collecting electrode" $\left(\mathrm{m}^{2}\right)$, the rate of gas flow $\left(\mathrm{m}^{3} / \mathrm{s}\right)$ respectively. The following relationship with current and voltage effects on the collection efficiency can be formulated as

$$
\eta=V n I
$$

Adjusting rules used to determine the value of PID controller parameters. The PID controller design parameter for this operation $k p=0.91417, T i=7$ second, $T D=0.28$ second, hence the best parameters of PID controller transfer function needed for best operation [15].

the output is the value of the DC voltage in Kilo Volt $(\mathrm{KV})$ from the - HVDCPS. The data is then fed to the identification toolbox of MATLAB ${ }^{\circledR} \mathrm{R} 2019 \mathrm{a}$ to find the continuous mathematical model. The closed-loop transfer function of the overall system can be formulated as [9].

$$
T(s)=\frac{Y(s)}{U(s)} \frac{6.88 s+2.681}{s^{3}+3.368 s^{2}+7.426 s+3.15}
$$

The mathematical model of ESP is built depending on input/output data to the system. Fig. 6 shows the schematic diagram for data gathering. The input data represented in Fig.7. is the trigger angle while the output data, which can be shown in Fig.8 is the value of the DC voltage from the power supply in kilovolt The data has been recorded from the PID controller.

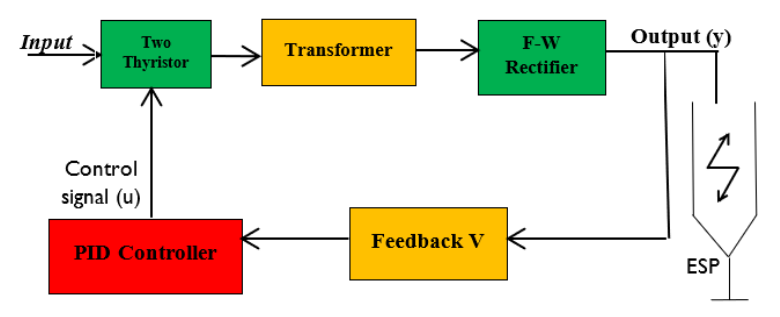

Fig.6. Input and output data gathering. 


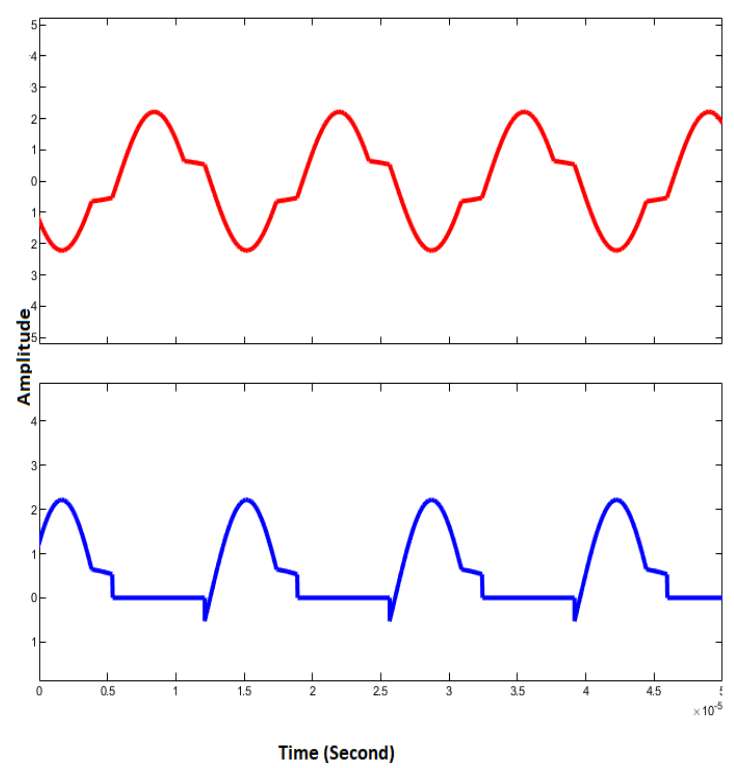

Fig.7. Input data to Thyristor

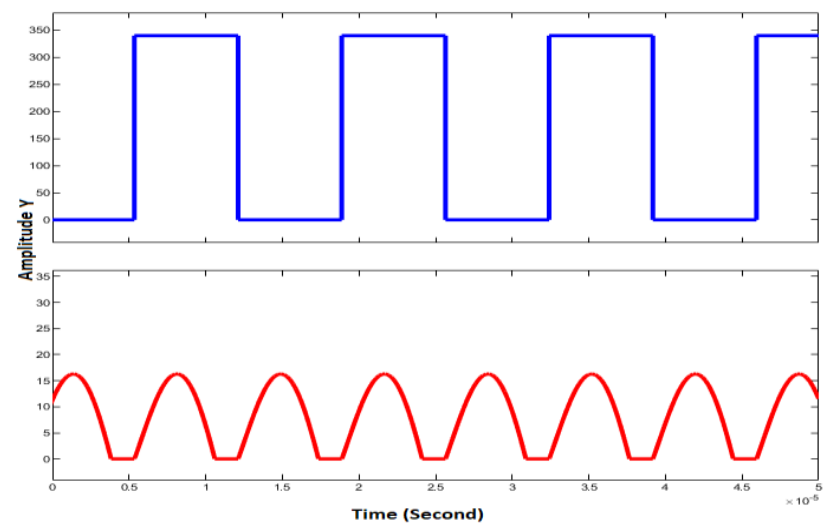

Fig.8. Output data of Full-wave Rectifier single phase

The Bode plot of the designed and simulated system is shown in Fig. 9. As illustrated in this figure, the stability and the performance of the closed-loop system is acceptable.

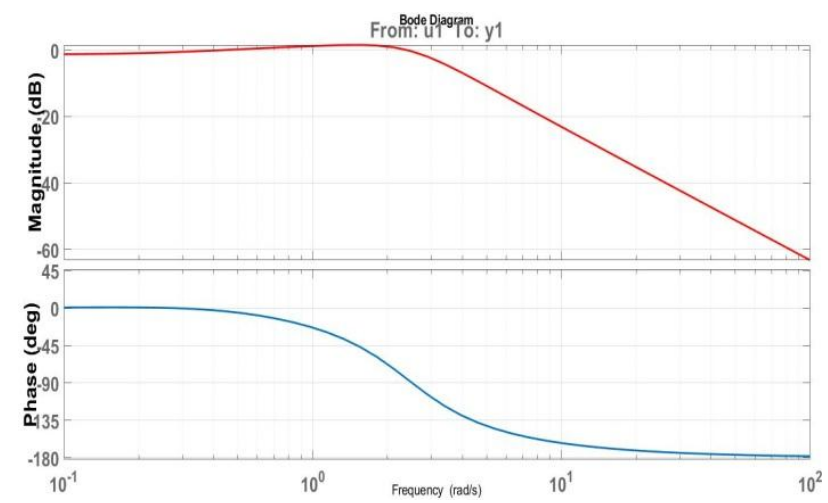

Fig.9. Bode plot of the designed system. 


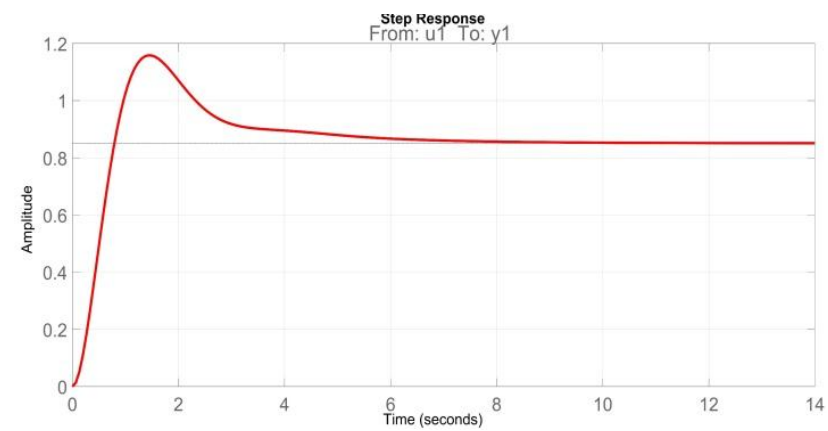

Fig.10. Step response of the mathematical model.

The PID tuner of the mathematical model to obtain the optimal value of PID to control the high voltage in ESP power supply as shown in Fig. 11.

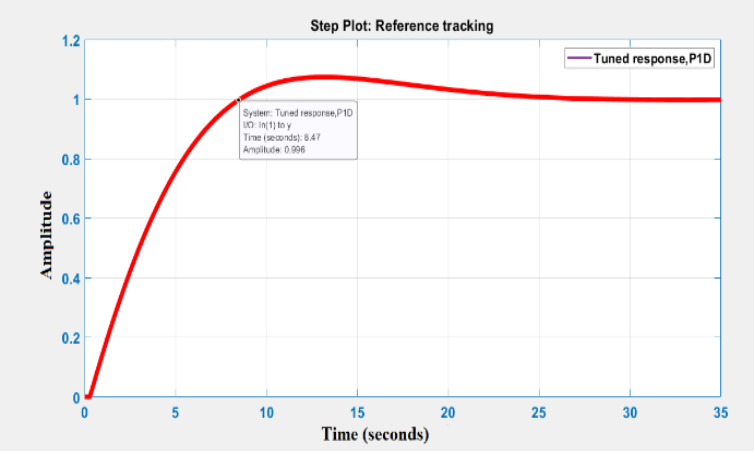

Fig.12. The PID Tuning of the mathematical model.

Implementation of the PID controller using MATLAB® R2019a according to the transfer function that gets it from the workspace depends on the value of alpha input and the voltage output as shown in Fig. 12 (a \& b).

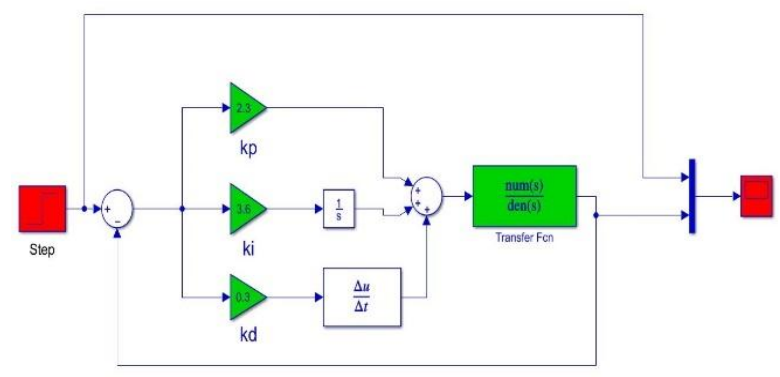

Fig.12. (a). Simulation of PID in MATLAB

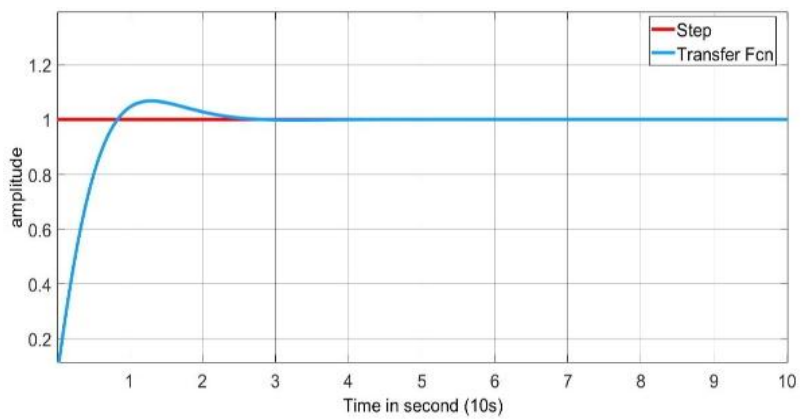

Fig.12.(b). Simulation of PID in MATLAB 
Simulation of the design of ESP with the PID controller using MATLAB® with input AC voltage source $340 \mathrm{~V}$ and $50 \mathrm{~Hz}$ and the output DC voltage $4 \mathrm{kv}$ the work of the design is in [16] but with single phase.

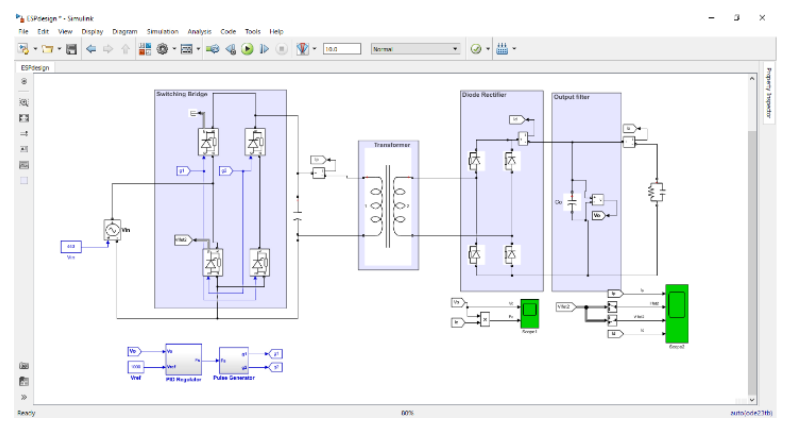

Fig.13. Schema of ESP with PID in MATLAB

\section{Technical Specifications}

The Bulletin 1763 MicroLogix $^{\mathrm{TM}} 1100$ PLC System (connected to power supply input:110/220V AC, 50HZ, Output: DC:24V/3A) is connected with the computer via Ethernet cable (pc need have standard Ethernet interface) as shown in Fig. 14. The PLC is programming by using RSLogix 500 Allen Bradley Family using analogue for input (voltage signal 0-10v or 4-20mA) and using the PID block in analogue to adjust the high voltage while the digital using for output as can be shown in Fig. 15 (a \& b).

PID simulation results give approximate values of reality, and these parameters can be used during the PLC program to control the high voltage feeding of the ESP power supply.

The actual comparison can understand error output in PID vs and error output in PLC. After performing the PID control action it shows some error but the PLC control system gives better performance.

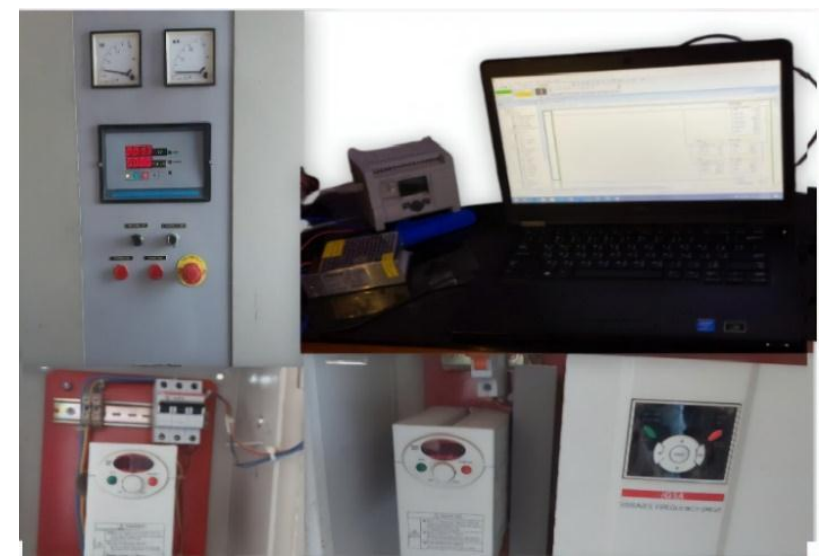

Fig.14. Communication between PLC, ESP\& PC

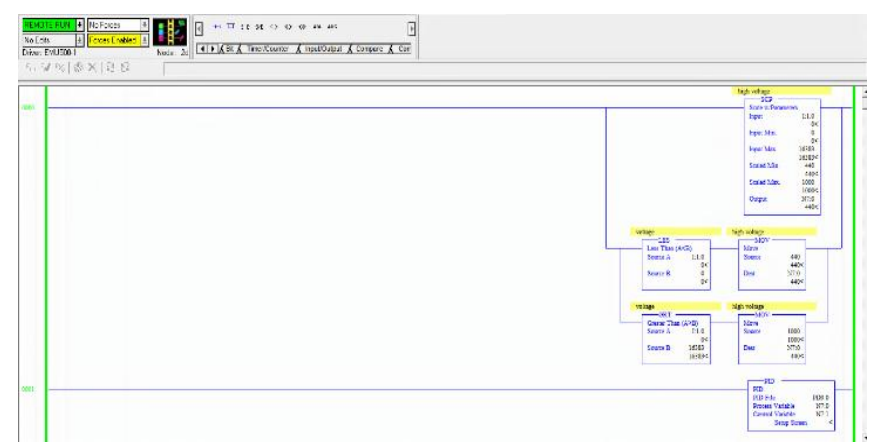

Fig.15.(a). PLC program with PID 


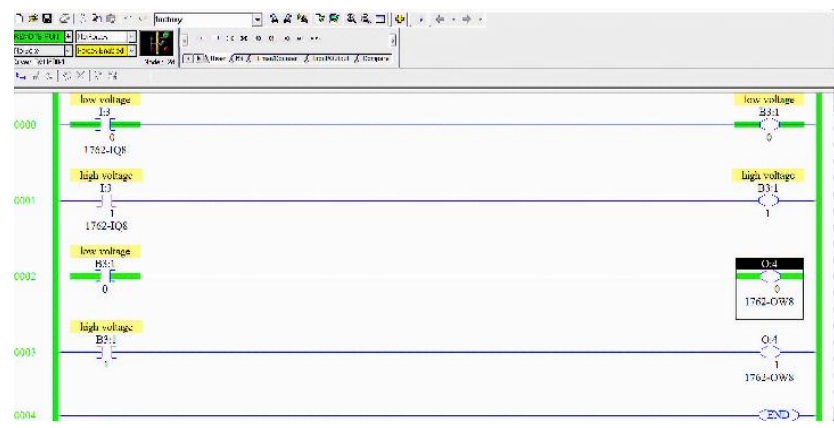

Fig.15.(b). PLC program with digital output

\section{Conclusion}

This paper shows the different control actions performed on PLC which gives reliable control to the high-voltage power supply of ESP. The results showed that when the PID controller is added, the steady-state error is reduced. The actual system output also matches the theoretical results, indicating the accuracy of the system transmission functions. At present, the parameters of the PLC controller should be set in the ladder diagram and can be adjusted in real-time. We have taken experimental values for PLC based on PID controller which are superior to other controllers due to its low fault response. in this work, we found out that utilizing of PLC important enhancements in the management can be made by using sensors, which complements the automation itself, and more efficiently solves the management problem.

\section{References}

[1] N. Selvi, R. J. I. J. o. P. Krithiga, and A. Mathematics, "AIR POLLUTION CONTROL-ELECTROSTATIC PRECIPITATOR," vol. 119, no. 12, pp. 1209-1218, 2018.

[2] M. J. Marie, G. A. Al-suhail, and H. T. J. I. J. o. C. A. Khadim, "Developing Al-Najaf Cement Plant using Wireless SCADA System," vol. 64, no. 13, 2013.

[3] K. Parker, Electrical operation of electrostatic precipitators (no. 41). IET, 2003.

[4] R. E. Samin, L. M. Jie, and M. A. Zawawi, "PID implementation of heating tank in mini automation plant using Programmable Logic Controller (PLC)," in International Conference on Electrical, Control and Computer Engineering 2011 (InECCE), 2011, pp. 515-519: IEEE.

[5] E. Priyanka, C. Maheswari, B. J. J. o. a. r. Meenakshipriya, and technology, "Parameter monitoring and control during petrol transportation using PLC based PID controller," vol. 14, no. 2, pp. 125-131, 2016.

[6] J. Xue and M. Lu, "Design of PLC-based electro hydraulic servo position closed loop system," in 2016 2nd International Conference on Materials Engineering and Information Technology Applications (MEITA 2016), 2017: Atlantis Press.

[7] M. F. Al Andzar, R. D. J. S. Puriyanto, and I. P. Letters, "PID Control for Temperature and Motor Speed Based on PLC," vol. 1, no. 1, pp. 7-13, 2019.

[8] V. Bhatkar, Distributed Computer Control Systems in Industrial Automation. Routledge, 2017.

[9] S. Chatterjee, V. J. I. J. o. E. P. Mukherjee, and E. Systems, "PID controller for automatic voltage regulator using teachinglearning based optimization technique," vol. 77, pp. 418-429, 2016.

[10] C. Li, N. Zhang, X. Lai, J. Zhou, and Y. J. I. S. Xu, "Design of a fractional-order PID controller for a pumped storage unit using a gravitational search algorithm based on the Cauchy and Gaussian mutation," vol. 396, pp. 162-181, 2017.

[11] A. R. Ajel, K. S. Gaied, and M. J. J. A.-K. E. J. Marie, "Wireless Network Control System for Electro Stati Precipitator in Cement Plants," vol. 13, no. 4, pp. 50-57, 2017.

[12] I. Ray and B. Altschuler, "WET ELECTROSTATIC GAS CLEANING SYSTEM WITH NON-THERMAL PLASMA FOR NOx REDUCTION IN EXHAUST," ed: Google Patents, 2018.

[13] S. De, S. J. I. S. Debnath, Measurement, and Technology, "Optimal switching strategy of an SVC to improve the power quality in a distribution network," vol. 13, no. 5, pp. 640-649, 2019.

[14] A. Zouaghi, A. Mekhaldi, R. Gouri, N. J. I. T. o. D. Zouzou, and E. Insulation, "Analysis of nanosecond pulsed and square AC dielectric barrier discharges in planar configuration: Application to electrostatic precipitation," vol. 24, no. 4, pp. 2314-2324, 2017.

[15] C. Nastasi et al., "Model based real-time networked applications for Wireless Sensor Networks," in 2009 IEEE International Conference on Pervasive Computing and Communications, 2009, pp. 1-3: IEEE.

[16] V. Reyes and B. Bidoggia, "Application of multi-phase HV rectifiers in electrostatic precipitators." 


\section{Authors' Profiles}

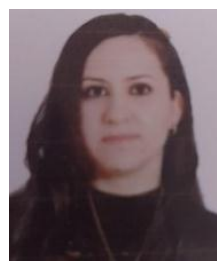

Rawnaq M. Afram received a B.Sc. in Computer Engineering in 2011 from Al-Nahrain University-Iraq. She is a computer engineer at the Ministry of Education and currently an M.Sc. student at Computer Engineering Department/ Al-Nahrain University-Iraq. Her research interest includes Controller and Computer engineering.

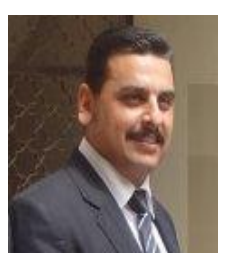

Anas A. Hussien received a B.Sc. in Electronics and Communications Engineering in 1999, M.Sc. in Electronics and Communications Engineering / Electronic Circuits and Systems in 2001, and Ph.D. in Information Engineering in 2007, from Al-Nahrain University. He is an associate professor since 2012 and head of the computer engineering department. Dr. Anas has published more than 12 published papers all of them in reputed journals and conferences

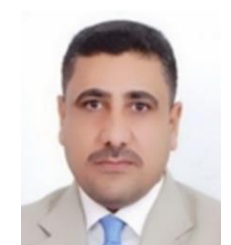

Mehdi J. Marie received his Bachelor's (1993), Master's (2004) Degrees from the University of Technology (Iraq), and Ph. D. from the University of Basrah (2014). He has been a lecturer of Control Theory I, II, Electronics, and Electrical Networks at Al-Nahrain University, College of Engineering. He is currently a senior engineer at AlZawaraa State Company, Ministry of Industry and Minerals (Iraq). Dr. Mehdi had achieved over seven Journal articles and two conference papers in the field of control and systems engineering. His current research and development interests are mainly in the following areas: self-tuning control and system identification, controller design for linear and non-linear systems, industrial applications particularly in the processing industry (for example refining, cement, plastic, and food industry).

How to cite this paper: Rawnaq M. Afram, Anas A. Hussien, Mehdi J. Marie, " Design and Implementation of Optimal PID Controller Using PLC for Al-Tahady ESP", International Journal of Image, Graphics and Signal Processing(IJIGSP), Vol.12, No.5, pp. 1-12, 2020.DOI: 10.5815/ijigsp.2020.05.01 